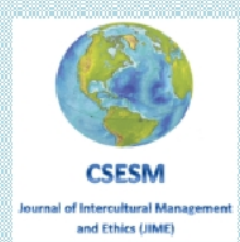

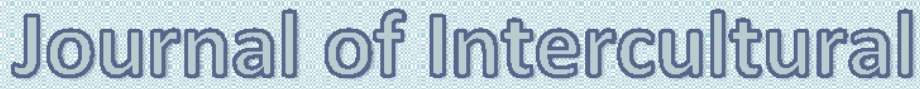

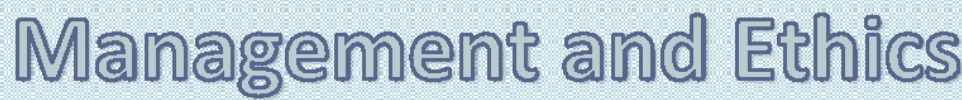

\author{
IOME
}

ISSN 2601 - 5749, ISSN-L 2601 - 5749

\section{published by zy \\ Center for Socio-Economic Studies and Multiculturalism \\ lasi, Romania \\ Waw csesmorg}




\section{Special Editor}

\section{Professor Beatrice Gabriela Ioan, PhD, MD}

Grigore T.Popa University of Medicine and Pharmacy of Iasi, Romania

E-mail: ioanbml@yahoo.com

\section{TABLE OF CONTENT}

Editorial ....

Beatrice Gabriela Ioan

Ethical Approaches on the Mandatory Vaccination in the Pandemic Context (Romania Case)

Andreea-Iulia Someșan, Ion Copoeru

Early Approaches in Management of Sars-Cov-2 Infection 19

Isabela-Ioana Loghin, Adriana-Florina Bahnă, Oana-Manuela Secrieru, Irina-Margareta

Nistor, Irina-Cristina Nicolau, Liviu Jany Prisăcariu, Florin Roșu, Victor Daniel Dorobăţ,

Cristin-Ioan Loghin, Carmen-Mihaela Dorobăț

Giving Birth during the Pandemic. How The Decision to Transform Certain Hospitals In Dedicated Covid-19 Medical Units Impacted Women on Psychological Level

Alexandra Ștefania Nadane

Evangelicalism in Uganda: Implications for Public Health and Bioethics

Sana Loue, Francis Bajunirwe

The Contribution of Ethics to the Development of the Healthcare System

Cornelia Margareta Găşpărel

Iatrogenesis Induced by Risk Reduction in Health Care

Mircea Gelu Buta

Ethical Contributions in Preserving the Dignity of the Terminal Patient

Elena Toader, Andreea Decusara, Mirela Piscuc, Tudor Winsinger

Ethical Aspects of the Institutionalization Process of Children from Outbreaks of

Tuberculosis

Rodica Gramma, Elena Cernăuțeanu, Adriana Paladi

Profession, Vocation, Mission or Work. The Ancient Physician and the Contemporary

Physician-Parallel Lives

Orsolya Horber, K.Zilahi 


\title{
GIVING BIRTH DURING THE PANDEMIC. HOW THE DECISION TO TRANSFORM CERTAIN HOSPITALS IN DEDICATED COVID-19 MEDICAL UNITS IMPACTED WOMEN ON PSYCHOLOGICAL LEVEL
}

\author{
Alexandra Ștefania Nadane \\ Doctoral School in Philosophy and Socio-Political Sciences \\ "Alexandru Ioan Cuza" University, Iasi, Romania \\ E-mail: alexandra.nadane@gmail.com
}

\begin{abstract}
:
The study evaluates how the decision to transform completely hospitals and some of the maternity wards into dedicated Covid-19 medical units psychologically impacted women who gave birth during the pandemic.

Prior research has shown that, during the pandemic, between $21 \%$ and $25 \%$ of pregnant women were confronted with higher levels of stress and emotional problems (Preis et al., 2020a; Preis et al., 2020b). At the end of March 2020, the maternity ward of the "St. John the New" Emergency County Hospital in Suceava was closed and pregnant women were redirected to other local hospitals. Soon, the shortage of hospital beds in these alternative medical units generated a crisis: the women who were about to give birth did not know where to go, while the medical system froze. In some cases, the doctors recommended birth at home.

The results of our research, carried out by means of interviews, indicate a higher level of incertitude and anxiety among women who gave birth in this period. The conclusions show that the negative psychological impact on these women would have been much reduced if they had been offered psychological support and accurate information during their crisis period.
\end{abstract}

Keywords: birth, pandemic, Covid-19, pregnancy crisis, Suceava

\section{Introduction}

On March $11^{\text {th }}$, 2020, the World Health Organization declared Covid-19 a global pandemic. Romania declared a state of emergency on March $16^{\text {th }}$ " "St John the New" County Emergency Hospital in Suceava, the most important hospital in Suceava county, was closed between March $23^{\text {rd }}$ and June $2^{\text {nd }} 2020$ and operated as a Covid-19 unit.

The obstetrics-gynecology department of "St John the New" County Emergency Hospital in Suceava has 85 beds (Suceava County Council, 2016) and is classified as a level 3 hospital (Ministry of Health, 2006). Level 3 corresponds to maternity hospitals properly equipped to manage high-risk births and babies who may be born with medical problems (Ministry of Health and Family, 2002).

In total, in Suceava County, which has a population of 634,810 inhabitants, there are 7 maternity hospitals; 5 of them are classified with level 1 (Ministry of Health, 2006). This level means that maternity hospitals can provide minimal medical care for pregnant women and newborns. Here, full-term physiological births can be performed on newborns without problems. In case of an emergency, cesarean section may also be performed, if the necessary means are available (Ministry of Health and Family, 2002).

In all the obstetrics-gynecology departments in the Suceava County there are 243 beds (Ministry of Health and Family, 2002). 
After the closure of "St John the New" County Emergency Hospital in Suceava, there were a few days of uncertainty in which the authorities and doctors did not know exactly what would happen to the women who were to give birth. Subsequently, the hospital management decided that the women who were going to give birth will be redirected to the other maternity hospitals in the county. Soon, problems began to appear: there were not enough beds available, there were not enough facilities to provide the necessary medical services, and some doctors became infected with the new coronavirus and could not work anymore.

To analyze the emotional impact generated by this crisis, we conducted 15 interviews with women from Suceava County, who gave birth during the period when the hospital was closed. The data were collected between November and December 2020. The present study has a limited scope, as it is a micro-research. It has been designed as a series of 15 online interviews with women from the county of Suceava who gave birth while "St John the New" County Emergency Hospital in Suceava city was closed and turned into a dedicated Covid-19 medical unit.

Prior research shows that 14 to $54 \%$ of pregnant women are usually confronted with emotional and mental health issues during pregnancy. This is generated by more causes: a) lack of social support, b) psychological instability before pregnancy which aggravates during pregnancy, c) health problems of the child (problems of development, probability to give birth to a child with certain health problems), d) risk behaviors affecting the mother's life (Madhavanprabhakaran et al., 2015).

Two more specific problems were added during the pandemic last year to the list above: the stress associated with the woman's feeling that she is not prepared to give birth and the stress related to the risk of contracting Covid-19. These factors subjected pregnant women to moderate-to-high levels of emotional pain (Preis et al., 2020a).

Zhou et al. (2020) conducted a study involving 1,123 women from the USA, who were either pregnant or had recently given birth. The results showed that $36.4 \%$ of them reported significant levels of depression, $22.7 \%$ expressed anxiety, $10.3 \%$ reported clinical signs of Post-Traumatic Stress Syndrome. Incipient proof indicates that pregnant women are confronted with moderate-to-high levels of psychological suffering during the Covid-19 pandemic (Saccone at al., 2020). Mappa et al. show that prenatal anxiety can be a risk factor for maternal mental health problems, can increase probability of postnatal depression, obstetrical complications, problems of fetal development, longer labor and premature birth (Mappa et al., 2020).

\section{Materials and Methods \\ Study design}

Each of the participants was invited to answer an interview with 11 open questions. The questions in the first part were designed with the goal of obtaining information about the pregnancy period: emotional states, relationship with the family and the community, with the obstetrician monitoring the pregnancy. The questions in the second part focused on experiences related to giving birth during the pandemic, on what happened before and after birth, on the interaction with hospital staff and the solutions found by participants to overcome the difficulties they were faced with.

The research was conducted online, through the snowball method, during November and December 2020.

\section{Participants}

This study included 15 women aged 18 to 41, residents of Suceava county. They gave birth while "St John the New" County Emergency Hospital in Suceava was closed because of the pandemic, being dedicated solely to Covid-19 patients. 


\section{Data collection}

The information collected through the online interviews was transcribed and organized in sections.

\section{Results}

Participants spoke in the interviews about the impact of the pandemic in their lives, about social isolation and the unexpected closing of the "St John the New" County Emergency Hospital in Suceava city and its transformation in Covid-19 unit.

The emotional balance most of them had experienced in the first part of their pregnancy turned into fear, uncertainty and even panic when the effects of the pandemic showed: social isolation, less access to medical services and, at the apex of the crisis, the closing of the "St John the New" County Emergency Hospital in Suceava city.

In order to analyze more easily the presence or absence of perceived support, perceived stress and the reasons of perceived stress, we have analyzed how the participants related to four types of relationships: with family, with friends and acquaintances, with their gynecologist-obstetrician, and with the staff of the maternity ward. Finally, we have attempted to understand how they perceived the evolution of their emotional state in the first part of their pregnancy, and also before and after birth. Please find below an analysis of their perceptions related to all these factors.

\section{Relationship with family}

For most participants, their positive relationship with the family was an important source of support both during pregnancy and in the crisis moments when they did not have access to pregnancy medical examinations, they had to change their monitoring obstetrician or to give birth in a different city:

"Family was more careful towards me. I am a happy case, since they protected me from the beginning and offered me all the support I needed to go through this experience and be well." view."

"They offered lots of support and understanding. I felt protected from this point of

Two participants said their relationship with the family was affected due to isolation and loneliness and the situation influenced their emotional state:

"It was quite weird that, for fear of not contracting the virus, you could not even get in touch with your parents."

From the discussions with the participants we have concluded there were two aspects which influenced their interaction with family members: whether the parents or the parentsin-law lived in the same house with them and whether the husband was exposed to a higherthan-usual risk of contracting the virus.

Pregnant women who lived with their partner and their parents or their in-laws perceived more support and had more social interactions during the restrictions period, compared to pregnant women who did not live with their parents or in-laws.

"It was difficult that we were not able to see the members of our family face to face".

"I live with my husband and his parents; therefore everything was just like before the pandemic".

The feelings of loneliness and fear were more acutely perceived by pregnant women whose partners were more exposed to the risk of getting infected and who isolated themselves at work, who came home less often or who isolated themselves in a separate room of the house:

"It is painful to live two meters away from your husband and not be able to hug him on your birthday while you are nine months pregnant. I cried. I felt lonelier than ever." 


\section{Relationship with the community (friends, colleagues)}

We have analyzed the participants' perception related to support offered by the community during their pregnancy in the context of the difficulties they experienced at the time. Colleagues and friends were perceived as the most important source of support after family support. 10 out of the 15 participants said that interaction with acquaintances during the pandemic significantly decreased:

"We haven't seen each other since the beginning of the pandemic, we interacted strictly online. It was quite difficult."

"It was during the pandemic, so all relations outside family were based on online communications via the phone and the Internet."

"Socially speaking, it wasn't exactly easy, because I did not see anyone except close members of the family."

"The relationship with many of my friends and colleagues was lost."

Perceived lack of support generated feelings of loneliness, uncertainty, the idea that pregnant women are left to face alone the new challenges: the pandemic and the closing of the hospital.

\section{Relationship with the gynecologist-obstetrician}

Talking about their relationship with their obstetrician during the closing of the "St John the New" County Emergency Hospital in Suceava, all the participants mentioned two aspects: the presence or absence of information on access to medical services; and presence or absence of emotional support from the obstetrician.

4 out of the 15 women said they received updated information and support from their obstetrician during the closure of the hospital and its conversion into a Covid-19 unit:

"He encouraged me as much as he could, despite the fact that, at the beginning of the pandemic, he did not know what would happen and how it would be to give birth in the Suceava hospital turned into Covid hospital."

"I wished he had been more empathetic, given the situation I was going through. But I understand it wasn't easy for doctors, either; we have all been affected by this pandemic."

The other participants were confronted with negative emotional states caused by uncertainty and lack of information:

"I was desperate, I would ask for advice from my gynecologist. There was no answer, I was 34 or 35 weeks pregnant, my term was coming and I yet did not know what to do."

"I felt so much need to talk to someone who knew my situation and had medical experience. I felt the need to share my little silly tribulations which usually occur in this period and to be assured that everything would be ok."

In their relationship with the gynecologist, many participants perceived lack of emotional support and lack of information regarding their access to medical services. The issue of the lack of information about medical services available goes beyond the doctorpatient relationship. In the context of the Suceava County Hospital crisis, it was rather caused by the way in which hospital management and authorities managed the situation.

To better understand the context, we need to mention the changes in hospital management: on March 24, the manager of "St John the New" County Emergency Hospital was dismissed. Between April 2 and 30,2020, the hospital was managed by a military team and on May 1, 2020 a civilian team took over the management.

\section{Relationship with the staff of the maternity ward}

14 out of the 15 participants to the study declared themselves satisfied with how they interacted with the maternity staff, including in terms of emotional support:

"I benefited of the necessary support and attention."

"Everybody wanted to encourage us, to help us be optimistic."

"A straight A grade for the staff." 
"They had a very positive attitude."

There is a significant contrast between perceptions related to the relationship with the gynecologist before birth and the way in which participants perceived their interaction with the medical staff of the maternity where they gave birth to their children.

This difference can be explained by the fact that the gynecologist-obstetricians were perceived by study participants not only as doctors who monitored their pregnancy, but also as representatives of the institution where they worked. It is likely that participants expected doctors to manage the public communication crisis created on the background of the sanitary crisis, although other bodies were formally in charge with institutional communication. Yet, such hypotheses need to be further verified and confirmed or infirmed by future studies which shall analyze in detail the perspective of the staff of the Suceava County Hospital in the period when it was closed and turned into a Covid-19 support unit.

\section{The evolution of emotional states in the first months of pregnancy, before and after birth}

We also analyzed women's perception of their emotional state at different times of their pregnancy: in the first months, before and after birth.

In the first months of pregnancy, participants were confronted on one hand with their fear of going to the hospital and on the other hand with the fact that, starting from March 2020, access to medical services was restricted:

"There was more uncertainty, difficulty in finding a hospital, a doctor to monitor you. The difficulty of standing in long queues for medical tests."

"Stress, since I had to find a gynecologist who had a private practice."

"At first I imagined the worst scenarios: that I would contract the virus, that I would not be able to carry my child in my arms, I thought of possible implications or medical complications, especially since everything was at the beginning and there was a high level of uncertainty. I had so many questions to which nobody could give a sure answer."

As the study participants' pregnancies came closer to term, the hospital was closed and turned into a Covid-19 unit. Most of their answers regarding their emotional state before birth refer to this:

"Up to the moment of giving birth I went through feelings of despair! I prayed that they reopened the hospital. There were all sorts of rumors. I didn't know what to believe anymore. There was the possibility that I would give birth to my baby in Fălticeni or Rădăuți, but it was my second child and I had to have a Cesarean section. Just as my term approached, people said the Fălticeni hospital had no anesthesiologist and the hospital of Rădăuți was infected."

"It was the most difficult moment of my life. Many hours spent without sleeping and in a general state of exhaustion."

"On the very tense moments when my pregnancy came closer to term I did not know where I would give birth, I did not know whether there would be a place for me, I did not know whether there would be somebody to assist me."

"I was so afraid that they would separate me from my baby".

The postnatal emotional states had two components: emotional states unrelated to Covid-19 pandemic experienced by pregnant women and emotional states related to the pandemic.

In the first category there were feelings of joy, tiredness, liberation, uncertainty (women at their first child), loneliness (women who did not benefit of social support).

"It was the greatest joy!"

"I felt full of joy, because I had met my baby."

"I suffered of postnatal depression, because there was nobody around me who had given birth and I had no idea what this change implied." 
The pandemic-related issues which generated negative emotional states in the participants were: separation from the child until the PCR test result came, situations in which either the mother or the child was infected with Sars-Cov-2 and they were separated, the impossibility of receiving the visits of their partners or relatives.

"I was optimistic until I was separated from my child. Afterwards, I wasn't myself anymore."

"Until the negative test result came in, I knew nothing about my baby. The Neonatology staff made medical visits only in the non-Covid wards."

"If my husband had been allowed to stay for an hour with the baby, I could have taken a shower, eaten in peace and slept a bit more than two hours out of 24; the experience would have been totally different."

At the end of the interviews we asked the participants what helped them to overcome difficulties more easily. Some of the participants found important support in their partners, in their family and in friends: "I felt how important my husband's support was"; "Those around me offered support when they found out I was pregnant".

In other cases, support came from communication with other pregnant women on social media or through support groups:

"Interaction with other women in similar situations through an online support group played a key role for me."

"The support groups on Facebook and other online support groups brought us closer to each other, helped us get moral support and encourage each other."

Some of the participants resorted to spiritual help in order to surpass difficulties:

"Faith in God played a key role for me. It helped me overcome difficulties."

\section{Discussion}

Previous studies mentioned in the introduction of this article (Preis et al., 2020a, Preis et al., 2020b, Saccone and colab., 2020, Mappa and colab, 2020) show that, during the pandemic, women are confronted with a high level of stress and with emotional problems. These problems can be caused by lack of social support, they can develop on pre-existing conditions (such as depression or risk behaviour), they can be linked to giving birth during the pandemic, or to fear of contamination with Sars-Cov-2.

A poll made in Great Britain to research pregnant women's perception on medical services during the pandemic show that two of the reasons for which women contact the maternity are related to their emotional state: anxiety and need for mental health support (Karavadra et al., 2020).

Brooks et al. (2020) show that pregnant women need information, coherent guidance and advice from the doctors and that the communication strategies designed by authorities need to include guidance for maintaining their emotional balance and mental health during the pandemic.

To respond to the emotional needs in these situations, the authorities can implement two support solutions:

1. Psychological support programs for prenatal and postnatal women. Such programs have been implemented in France, where three maternities offered psychological support over the phone for 10-12 days after birth and monitored the evolution of the women's emotional state for 6-8 weeks (Viaux et al., 2020).

2. Medical experts need to be trained in offering emotional and psychological support (Motrico et al., 2020).

\section{Conclusion}


The results of this research show that the unexpected closure of "St John the New" County Emergency Hospital in Suceava city and its transformation into a dedicated Covid-19 medical unit had a negative emotional impact on participants who gave birth between March 23rd and June 2nd 2020. They experienced panic, fear, and uncertainty, situations in which they did not know where they would give birth, moments when they were redirected to other hospitals in the region and they no longer had the logistics needed to give birth. In some cases, communication with gynecologists and the hospital was abruptly interrupted, and women felt alone and without alternatives. These conditions were amplified by a lack of upto-date information, a decrease in access to medical services and a lack of psychological support from the hospital and the authorities.

In the context of personal relationships, participants who had the support of their partner, family and friends could better manage difficult moments. In other cases, support came through communication on social networks and by taking part in online support groups. The results of the study can provide information to authorities and medical professionals on the emotional problems faced by pregnant women in certain circumstances, such as the pandemic context or other crisis situations. Knowing that pregnancy and childbirth are times when women are most vulnerable can help authorities when they are urged to make critical decisions related to closing a maternity ward. For example, when making the announcement that a maternity hospital is closing, an announcement about alternatives and support solutions could also be issued. An alternative may be the cooperation between the state medical system and the private medical system to take over the cases that can no longer be managed by the state hospitals in the region. It is an expensive alternative and can be difficult in a certain economic context, but births cannot be postponed or rescheduled, as it was the case with nonessential medical interventions.

To alleviate the negative emotional impact during health crises, maternity hospitals can provide psychological support for women before and after childbirth. To develop support, undergraduate or postgraduate training programs may include courses focused on emotional support during pregnancy.

The results of our study offer a perspective on experiences lived by participants at the time of giving birth and open new directions for more in-depth research in the future.

\section{Limitations of the study}

The present study is a micro-research made on a small group of 15 participants. One of the limitations of the study is the small number of participants. Because of this limitation we cannot have a full knowledge of the psychological impact on pregnant women generated by the decision to close "St John the New" County Emergency Hospital in Suceava and turn it into a Covid-19 unit.

Another limitation is that the study does not take into account the perspective of medical professionals, hospital management and authorities towards the closure of "St John the New" County Emergency Hospital in Suceava city. We hope that these will be the subject of more extensive future studies.

\section{References}

Brooks, S. K., Weston, D., \& Greenberg, N. (2020). Psychological impact of infectious disease outbreaks on pregnant women: Rapid evidence review. Public Health, 189, 26-36.

Karavadra, B., Stock1, A., Prosser-Snelling, E., Simpson, P., \& Morris, E. (2020). Women's perceptions of COVID-19 and their healthcare experiences: a qualitative thematic analysis of a national survey of pregnant women in the United Kingdom. BMC Pregnancy and Childbirth, 20(1), 1-8. 
Madhavanprabhakaran, G. K., D’Souza, M. S., \& Nairy, K. S. (2015). Prevalence of pregnancy anxiety and associated factors. International Journal of Africa Nursing Sciences, 3, 1-7.

Mappa, I., Distefano, F. A., \& Rizzo, G. (2020). Effects of coronavirus 19 pandemic on maternal anxiety during pregnancy: a prospectic observational study. Journal of Perinatal Medicine, 48(6), 545-550.

Ministry of Health. (2006). Order no 1881/2006 for ranking Obstetrics-Gynecology and Neonatology hospital units, sections and compartments. Romanian Official Monitor, Part I, no. 59/25.01.2007. https://lege5.ro/gratuit/geydcmzwhe/ordinul-nr-1881-2006privind-ierarhizarea-unitatilor-spitalicesti-a-sectiilor-si-compartimentelor-deobstetrica-ginecologie-si-neonatologie.

Ministry of Health and Family. (2002). Order no 910 of 18/11/2002 for ranking the specialized Obstetrics-Gynecology and Neonatology hospital sections, with subsequent additions and WHO 272/2009 amendments.

https://www.dsp-galati.ro/images/stories/2017/custom/OMS910compilatOMS272.pdf.

Motrico, E., Mateus, V., Bina, R., Felice, E., Bramante, A., Kalcev, G., ... \& Mesquita, A. (2020). Good practices in perinatal mental health during the COVID-19 pandemic: a report from task-force RISEUP-PPD COVID-19. Clínica y Salud, 31(3), 155-160.

Preis, H., Mahaffey, B., Heiselman, C., \& Lobel, M. (2020a). Vulnerability and resilience to pandemic-related stress among US women pregnant at the start of the COVID-19 pandemic. Social Science \& Medicine, 266, 113348.

Preis, H., Mahaffey, B., Heiselman, C., \& Lobel, M. (2020b). Pandemic-related pregnancy stress and anxiety among women pregnant during the coronavirus disease 2019 pandemic. American Journal of Obstetrics \& Gynecology MFM, 2(3).

Saccone, G., Florio, A., Aiello, F., Venturella, R., De Angelis, M. C., Locci, M., ... \& Sardo, A. D. S. (2020). Psychological impact of coronavirus disease 2019 in pregnant women. American Journal of Obstetrics \& Gynecology, 223(2), 293-295.

Suceava County Council. (2016). Decision no 238 of 23.12.2016 for the approval of the organizational chart of "St John the New" Suceava County Hospital. http://www.cjsuceava.ro/2016/hotarari_adoptate/248.pdf.

Viaux, S., Maurice, P., Cohen, D., \& Jouannic, J. M. (2020). Giving birth under lockdown during the COVID-19 epidemic. Journal of Gynecology Obstetrics and Human Reproduction.

Zhou, Y., Shi, H., Liu, Z., Peng, S., Wang, R., Qi, L., ... \& Zhang, X. (2020). The prevalence of psychiatric symptoms of pregnant and non-pregnant women during the COVID-19 epidemic. Translational psychiatry, 10(1), 1-7. 